\title{
¿Sociedad de conocimientos o culturas de saber?
}

Mario Mendez ${ }^{16}$

\section{Resumen}

Las siguientes páginas presentan una aproximación crítica a la pretensión de comprender la educación a partir de su ajuste a la denominada "sociedad del conocimiento", "sociedad de la información" o "sociedad del aprendizaje", categorías todas frecuentemente utilizadas para describir el tipo de producción de la riqueza correspondiente a la sociedad postindustrial.

\section{Introducción}

El tema de la "sociedad del conocimiento" 17 aparece frecuentemente ligado a otros como "sociedad de la información" -con la cual se la suele hacer coincidir-, "economía basada en

Docnir en Filosofia, docente de la Escuela Ecuménica de Ciencias de la Religión, Univensidad Nacional, Cosra Rica.

Sociedaj del conocimiento" es una noción que fue utilizada por primera vez en $19 e+$ per el auseriaco Peter Drucker, en relación al tema de la gestión. Drucker mezcla socielab al canocimiento" y Global Shopping Center (el "centro comercial glubal"), 
el conocimiento" (EBC), tecnologías de la información y la comunicación (TIC), revolución digital, economía digital, nueva economía, globalización, acceso a la tecnología, gestión del conocimiento, economía del conocimiento, creatividad, innovación, acreditación, formación del recurso humano, inversión en educación, capital intelectual, patentes, competitividad, sociedad de la innovación, entre otros.

Basta analizar la anterior lista, para deducir que cuando nos referimós a la sociedad del conocimiento, estamos frente a un tema más económico que pedagógico. Edwin Aguilar afirma que "la sociedad de información es un concepto maduro y aceptado como propuesta socioeconómica, en la cual los habitantes tienen acceso a redes de datos y aplicaciones comerciales, financieras, de salud, educación, cultura, servicios públicos y otros, que mejoran su nivel de vida (educación, salud, empleo y promoción social). En lo económico se concibe que la información y los productos de la tecnología de información y comunicaciones son commodities, y las empresas que producen o usan intensivamente estas tecnologías son un sector importante de la producción" 18 . Por su parte, Luis Joyanes enfatiza que "en esta

refiriéndose al desarrollo de las empresas de talla mundial y al auge de las industrias, las redes de información, la liberación del peso de las fronteras a los gestores de la producción, consumidores y productos, la interconexión en un mercado único que se autorregularía per se, en la tradición de la "mano invisible" de Adam Smith. Para Drucker, en un sistema capitalista el recurso fundamental es el capital, el cual es entendido como separado y opuesto al trabajo. En la nueva sociedad, el principal recurso es el conocimiento: capital y trabajo se identifican en el trabajador-conocedor. Cfr. Entrevista de Jorge Nascimento a Peter Drucker, en Executive Digest, versión digital en http:// www.gurusonline.rv/uk/conteudos/drucker4.asp.

18 AGUILAR Edwin, Sociedades del futuro, en El Financiero, San José, 2 de mayo 2005. Sin embargo, en la práctica no sucede así: nunca habíamos tenido tanto acceso a redes como hoy, sin embargo el 18 de septiembre de 2009, The Economist, comentando la crisis financiera de Estados Unidos, afirmaba que "la producción está disminuyendo en Japón, Alemania, España y Gran Bretaña, y es escasamente positiva en muchos otros países" (Las finanzas globales están siendo desgarradas pero se pueden restaurar, publicado en español por La Nación, 19 de septiembre 2009, San José, p 23 A.). Por su parte, la CEPAL ha advertido que en el año 2009 -un año en el que creció significativamente la conectividad en el continente- tendríamos 10 millones de nuevos pobres en América Latina. Cfr. 
sociedad, la información, como actividad y como bien, es la principal fuente de riqueza y principio de organización"19.

Cualquier análisis de la producción académica sobre el tema de la sociedad del conocimiento, revela -ademásque quienes más se interesan por definir y describir tal sociedad son los especialistas en desarrollo productivo y empresarial, así como los especialistas en comercio internacional, más que los pedagogos.

Se trata, sin embargo, de un tema vinculado a la educación. La sociedad del conocimiento es frecuentemente relacionada con los sistemas educativos de los estados, especialmente con la formación profesional, con la educación superior y con la adquisición de competencias informáticas; además forma parte importante del vocabulario de las reformas educativas y es preocupación permanente de muchos centros de estudios superiores.

El frecuente uso de de la expresión "sociedad del conocimiento" en ámbitos tan diversos como la economía ${ }^{20}$, la pedagogía ${ }^{21}$, la informática o las ciencias de la religión ${ }^{22}$, ofrece una idea del peso que tiene el tema en el discurso académico actual, aunque no en todos los ámbitos es abordado de la misma manera ni en todos los campos del saber tiene el mismo peso.

Ante la llamada sociedad del conocimiento, cabe, por tanto, una postura crítica que nos permita a los educadores

\footnotetext{
Ka.CSBerG Bemando, Lamoamérica: nuevos desafios, en La Nación 22 de agosto de 2006. venifindigital en hrtp://urum nacion.com/ln_ee/2008/agosto/22/opinion $1671210 . \mathrm{html}$ 35 MYANES Lais, Cibersociedad. Los retos sociales ante un nuevo mundo digital, Ed. Mc. Graw HAll Matind 1997, p. 4.

I El nema de la saciedad del conocimiento es frecuente, por ejemplo, en el semanario El Finmaena puhlicabo por el Grupo Nación, en Costa Rica.

Ver, por esempla, las diferentes ponencias del II Congreso Iberoamericano de Eduaciin 1 Sociedad del Conocimiento, celebrado en la Universidad Nacional, Heredia, Cisea Bica en segriembre de 2008 .

CF R.MEIES A manda, Repensar la religión. De la creencia al conocimiento, EUNA.

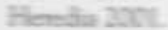


y educadoras asumir tal categoría convencidos de que es útil y adecuada en el contexto en que vivimos, o bien repensarla, sustituirla, o complementarla con otras que nos ayuden a entender nuestro entorno y a dar respuesta a los desafíos de los hombres y mujeres de hoy.

En concreto, sugiero que aquí nos planteemos interrogantes como las siguientes: ¿es esta "la" sociedad del conocimiento o es sólo "una" sociedad del conocimiento que -como otras tantas en diferentes épocas y espacios geográficos- tiene unas características que la distinguen?; ¿es realmente el conocimiento -entendido como factor de producción y como canal para la producción de riqueza- lo que distingue la vida cotidiana de la mayoría de los seres humanos de hoy?, ¿los educadores y educadoras podemos legítimamente asumir el conocimiento así entendido como el fin primario de la educación?, ¿qué alternativas educativas podemos generar?

\section{El conocimiento como estrategia para el crecimiento económico}

A la sociedad del conocimiento se suele hacer alusión cuando se quiere describir la forma de producción y distribución de la riqueza que sustituyó o está sustituyendo a los modelos de producción basados en la actividad agrícola y en la actividad industrial.

Si hace tres siglos la humanidad presenció la revolución industrial -y acomodó la educación a tal revolución ${ }^{23}$. hoy somos testigos de la revolución digital -y somos invitados a ajustar la educación a la sociedad del conocimiento

\footnotetext{
23 Ivan Illich advertía que la escuela "como organización con su correspondiente ideología, no constituye un dogma eterno, sino un simple fenómeno histórico que aparece con el surgimiento de la nación industrial". Iván ILLICH, En América Latina, ¿para qué sirve la escuela?, Ed. Búsqueda, Buenos Aires 1974, p. 16.
} 
que surge como consecuencia y causa de tal revolución. Se dice, entonces, que nos encontramos de lleno en la sociedad de la información o basada en el conocimiento, representada por una economía digital, en la cual el conocimiento constituye el principal recurso y un poderoso motor para el crecimiento, la competitividad y el empleo.

En el siglo XIX, los jóvenes estados centroamericanos utilizaron la educación como mediación para la construcción y difusión del sistema de signos -mitos fundantesen los que se apoyó la identidad colectiva (fin político) y para la formación de los cuadros laborales necesarios para el sistema económico (fin económico). La educación fue "el vehículo, el medio y el camino hacia el reconocimiento pleno del sujeto en un orden social, orgánicamente concebido en función de la aplicación del conocimiento, de la ciencia y del desarrollo tecnológico como factores necesarios para la producción y reproducción del orden capitalista y, en general de la "sociedad". La educación se constituyó en el canal orgánico de la producción y reproducción simbólica de la realidad social, del Estado y de la "sociedad"'24. De nuevo en esa descripción de Maynor Mora aparecen los fines sociales y económicos de la educación y del conocimiento ${ }^{25}$. Ahora sin embargo -dice Mora- ese Estado debilitado ha sido sustituido por otros actores dominantes: las transnacionales. En nuestros días "la cuestión de la funcionalidad social de la educación se ve reducida a los límites reproductivos de ese orden de cosas, bajo el llamado nacional a seguir los derroteros de la globalización económica y debilitadas promesas de bienestar, cuya única función es de orden propagandístico y mediático"26.

MORA Mapnoc, Op. Cit., p. 73-74.

Pan ampliar de estudio sobre los fines de la educación, especialmente açuéllos polítés sec mímicos, ver SANCHEZ Juan José, Escuela, sistema y sociedad, Ed. Libertarias, Mebir 199L pg: 140-153.

ind $=75$ 
En autores como Mariano Corbí es fácil rastrear esa relación entre sociedad de conocimiento y producción de riqueza. Según Corbí, "estamos frente a la aparición, consolidación y expansión de un nuevo tipo de sociedad: la sociedad del conocimiento; es decir, una sociedad que vive, se desarrolla y prospera creando y consumiendo continuamente un bien sutil: el conocimiento. Esta sociedad, por su misma naturaleza y propósito, está formada por grupos que se ven forzados a aprender continuamente, que se ven obligados a adaptarse continuamente a nuevos problemas, nuevas perspectivas, nuevas soluciones en todos los campos"2?

Para Corbí, "en la primera revolución industrial, el sistema educativo evolucionó a fin de llegar a producir trabajadores aptos para una economía basada en la fábrica. La antigua fábrica requería hombres pacientes, dóciles, capaces de soportar el aburrimiento y capaces de adaptarse al ritmo de las máquinas en horarios regulares y en un sistema de vida regular. Eso es lo que la educación tenía que producir. En la segunda revolución industrial, en la escuela del futuro, en cambió, el objetivo será aprender a crear y, por tanto, aprender a pensar y, sobre todo aprender a aprender." ${ }^{28} \mathrm{La}$ educación, por lo tanto, tiene que ser ajustada para producir sujetos adecuados a las nuevas formas de producción de riqueza: formas de producción que exigen flexibilidad, creatividad, adaptabilidad, capacidad de anticiparse a los acontecimientos.

Con un optimismo quizá exagerado, Corbí cree que el desarrollo de los instrumentos (computadoras, satélites, etc.) permitirá "que en los guetos más pobres se pueda disfrutar de los mismos cursos, de los mismos prestigiosos profesores, de las mismas recónditas asignaturas que en las escuelas de las elites" ${ }^{29}$. Si embargo en la práctica ha sucedido 17 CORBí Mariano, Proyectar la sociedad, reconvertir.la religión, Ed. Herder, Barcelona 1992, p. 22-23.

2 Ibid, p. 54 .

Idem. 
lo contrario, al menos en los países pobres. En Costa Rica, por ejemplo, que tiene la más extensa red de computadoras en Centroamérica ${ }^{30}$, cada vez es menor el porcentaje de estudiantes que comienza la etapa de bachillerato (sólo 3 de cada 10), y la deserción escolar es motivo de gran preocupación por parte de las autoridades educativas. Como en el resto de Centroamérica, la educación secundaria costarricense está cada vez más en manos de centros privados que suelen incluir como criterio de calidad educativa la posesión de equipos de cómputo y de redes y a los que no tienen acceso los jóvenes y las jóvenes más pobres.

\section{2. ¿Se puede universalizar la sociedad del conocimiento?}

¿Es el conocimiento el rasgo que distingue a nuestro tiempo y a nuestras sociedades? Pareciera que si quisiéramos ser honestos con la realidad tendríamos que dar una respuesta negativa: "Cada año perecen diez millones de párvulos, que lo que más los distingue de otros galopines del mundo es un estómago vacío, un rostro triste y un cerebro atrofiado por la desnutrición. Ellos provienen de esa multitud paupérrima de 2.500 millones de seres miserables, que sobreviven con uno o dos dólares al día y abarcan el $40 \%$ de toda la humanidad, pero apenas disponen del $5 \%$ del ingreso mundial. La asimetría es tan sideral, que en el otro extremo de esa polarización, el $20 \%$ de la población del planeta disfruta del $80 \%$ de la riqueza mundial, y el ingreso total de los 500 magnates más acaudalados equivale al de 416.000 .000 seres famélicos del Tercer Mundo" ${ }^{131}$. Esta

\footnotetext{
30 Costa Rica aparece como el tercer país de América Latina más desarrollado tecnológicamente en el Informe Global sobre Tecnología 2007-2008, elaborado por el Foro Económico Mundial. El país se ubica en el puesto número 60 a nivel mundial y lo preceden Chile, que aparece en la posición 34, y México, en la 58. Cfr. htrp://www.centralamericadata.com/ es/article/business_commerce, consultado en Septiembre de 2008.

MADRIGAL Rodrigo, Globalización del hambre, en Diario Extra, San José 5 de agosto de 2008, versión electrónica en hetp://www.diarioextra.com/2008/agosto/05/ opinion 14.php.
} 
descripción de la realidad del mundo acentúa la sospecha de que no es precisamente el conocimiento lo que caracteriza la vida cotidiana de la mayoría de habitantes del planeta, sino la crisis.

Ignacio Ramonet ha advertido recientemente que "por vez primera en la historia económica moderna, tres crisis de gran amplitud -financiera, energética, alimentaria- están coincidiendo, confluyendo y combinándose. Cada una de ellas interactúa sobre las demás, agravando así, de modo exponencial, el deterioro de la economía real" ${ }^{\prime 32}$. El mismo Ramonet advierte que de la crisis financiera ya se ha pasado a la crisis social y que ya en julio de 2008 en unos cuarenta países, la carestía de los alimentos había provocado levantamientos y revueltas populares. A todo ello habría que añadir la ya alarmante e irreversible crisis ambiental que sufre el planeta.

También Franz Hinkelammert usa la palabra "crisis" para describir las consecuencias de la actual de estrategia de globalización neoliberal. Según Hinkelammert, "al transformarse este capitalismo en sistema mundial único acompañado de su pensamiento único, entra en crisis. No se trata de una crisis coyuntural ni una crisis de la acumulación de capital en el interior del sistema. Entra en crisis como consecuencia de la amenaza global de la reproducción de la vida humana, que el capitalismo produce hoy como su efecto indirecto" ${ }^{13}$. Esas crisis -la exclusión de grandes partes de

\footnotetext{
32 RAMONET Ignacio, Las tres crisis, en Le Monde diplomatique (Julio 2008) N²153. Por su parte, el Secretario General de la ONU, en una artículo difundido en octubre de 2008, afirmaba que "todos reconocemos los peligros de hoy. Una crisis financiera global. Una crisis energética global. Una crisis de alimentos global. Las conversaciones sobre comercio colapsaron, una vez más. Existen nuevos estallidos de guerra y violencia. El cambio climático amenaza cada vez más claramente nuestro planeta". Ban Ki-moon, El estado del mundo, en La Nación, 05 de octubre de 2008, versión electrónica http:// www.nacion.com/ln_ee/2008/octubre/05/opinion 1725883.html.

33 HINKELAMMERT Franz, El sujeto y la ley. El retomo del sujeto reprimido, EUNA, San José 2002, p. 24.
} 
la población humana, la subversión de las mismas relaciones humanas y la progresiva destrucción del medio ambiente-muestran, según Hinkelammert, la irracionalidad de la razón del mercado: una racionalidad que, además, se presenta como "sin alternativas".

Raúl Fornet Betancourt, por su parte, expresa su sospecha de que la "sociedad del conocimiento" no es un "constructo" adecuado para caracterizar la realidad epistemológica en las sociedades actuales, pues responde a una cultura dominante hoy, con su mito de historia lineal y progreso científico $^{34}$. Este conocimiento con el que se pretende caracterizar a la sociedad de hoy es el conocimiento científico-técnico que "desde la cesura de la modernidad centroeuropea capitalista, funge como fuerza de cohesión de un proyecto civilizatorio cuyo compás interior es el dinero" 35 . Ese conocimiento estaría, por lo tanto, estrechamente vinculado a estrategias de cálculo y de control, así como a políticas de dominio en todos los ámbitos de la vida humana; es la forma de conocimiento típica de la cultura occidental, por lo que no es universal ni por su génesis ni por los resultados de su expansión colonizante. Hablamos, entonces de sociedades que, debido a la dinámica de constante innovación a que las lleva su fundamento científico - tecnológico - mercantil, deben ser caracterizadas como sociedades de información o de conocimiento, y que sería justamente el tipo de sociedad en que vive la humanidad hoy, o al menos la parte de la humanidad que "cuenta" para el crecimiento y desarrollo "económico"36.

\footnotetext{
34 Cfr. FORNET BETANCOURT Raúl, La religión y su crisis actual vistas desde la filosofía, en Sociedades de conocimiento: crisis de la religión y retos a la teología. Seminario de teólogos y teólogas, 4-6 de abril del 2005, UNA, Heredia 2006, p. 40.

35 Ibid, p. 41.

36 Raúl FORNET-BETANCOUR, Introducción, o de la pregunta: ¿cómo pensar el saber que debemos saber?, documento policopiado, p. 3.
} 
Fornet Betancourt añade un elemento más para una crítica a la sociedad del conocimiento: la constatación de que no todas las sociedades han asumido -ni tienen por qué asumir- esa forma de entender el conocimiento. Todas las sociedades, pues, han sido y son sociedades del conocimiento a su manera ${ }^{37}$.

Se trata, además, de un tipo de conocimiento que por la fuerza con que se impone -la fuerza impositiva, expansiva y homogenizadora del proyecto de la modernidad capitalista-, ha causado lo que Fornet Betancourt ha llamado violencia epistemológica, es decir, la deslegitimación de las distintas culturas del saber, que se ha expresado en saberes tachados, en alternativas científicas marginadas, en desvalorización de las distintas culturas del saber ${ }^{38}$.

\section{Otras tipificaciones de la sociedad.}

El "conocimiento" no es la única categoría usada para describir lo que pasa hoy en el mundo. Es sólo una perspectiva entre otras. $\mathrm{Y}$ a los educadores nos conviene conocer otras perspectivas, otros "relatos" del mundo. Este mundo que hemos construido también ha sido descrito con categorías como "sociedad de masas", sociedad de la imagen", sociedad de consumo», "sociedad de la innovación", "sociedad de riesgo", "sociedad de la comunicación", "sociedad del aprendizaje", entre otras. Algunos de esos descriptores indican una postura optimista y condescendiente con la realidad en que vivimos. Otros, en cambio, manifiestan una postura más crítica y generadora de alternativas. Detengámonos en algunas de ellas -"sociedad del control", "sociedad del riesgo", "sociedad de la comunicación"- con el simple propósito de verificar que cada descriptor representa una pers-

\footnotetext{
37 Cfr. Idem.

38 Cfr. Idem.
} 
pectiva, una forma distintiva de entender al ser humano, al mundo y las relaciones que establecemos con otros seres humanos y con el mundo. Tales perspectivas seguramente son legítimas, pero no podemos absolutizarlas, precisamente por ser eso: perspectivas que debieran complementarse, dialogar, y -a través del diálogo- interpelarse sobre sus reales posiblidades de aportar a la reproducción de vida.

Según Castor Bartolomé, la nuestra puede ser descrita como la sociedad de control, en la que-mediante infinidad de dispositivos de poder- se dinamizan proyectos de construcción de subjetividades que corresponden a las estructuras de la sociedad. Para Bartolomé, la "sociedad de control" es una categoría epistemológica con la que se puede hacer la radiografía de los dispositivos de poder que se están configurando en el seno de las sociedades contemporáneas ${ }^{39}$. Son los dispositivos de control de la sociedad globalizada, que sustituyen a los anteriores dispositivos de control autoritarios vinculados al uso de la fuerza y al dominio sobre la vida (por ejemplo, el ajusticiamiento, el castigo físico ejemplar, etc).

Mediante los dispositivos de control -muchos de ellos vinculados a la escuela y a otros espacios educativos- se crean nuevas formas de dominación real, mientras se maneja ampliamente el discurso sobre la libertad (formal). Eso ha sido posible porque, según Bartolomé, "la sociedad del control desarrolló un amplio conjunto de saberes sobre la producción del deseo, saberes que sirven de sustentación a la creación de dispositivos de control que a su vez direccionan o inducen los deseos de los individuos" ${ }^{40}$. De esa manera se

\footnotetext{
39 Cfr. BARTOLOMÉ RUIZ Castor, Sociedad de control, en SALAS Ricardo (coordinador), Pensamiento Crítico Latinoamericano, Vol. III, Ed. UCSH, Santiago 2005, p. 948 40 Ibid, p. 950. En esta misma línea se coloca Maynor Mora cuando describe como la función articuladora de otras funciones de la educación, "el control, contención y subli. mación de las energías libidinales-utópicas de la niñez y la juventud" MORA Maynor, Avatares del sujeto. Imaginación, intelecto, educación, EUNA, Heredia2005, p. 73.
} 
consigue la sujeción de los individuos a los objetivos estructurales, y los individuos cooperan de forma activa con las estructuras vigentes: "La sociedad de control tiene como paradigma la sujeción del individuo a las demandas del sistema, y como eje principal de sus dispositivos de poder la producción de subjetividades flexibilizadas que se adapten cooperativamente a esas demandas" ${ }^{\prime 1}$.

Nuestras sociedades también ha sido descrita con la categoría "riesgo". Por ejemplo, ya en los años 80 , Ulrich Beck introducía y popularizaba el concepto de "sociedad del riesgo" ${ }^{\prime 2}$. Para este autor, en nuestros días la tecnología ha creado nuevas formas de riesgo e imponen una peligrosidad cualitativamente distinta a la del pasado. Según Beck, nos encaminamos hacia una nueva modernidad en la que el eje que estructura nuestra sociedad industrial no es ya la distribución de bienes sino de males. No es la distribución de la riqueza, sino la distribución del riesgo, lo que moviliza hoy a numerosos colectivos sociales. Beck iniciaba así un artículo titulado De la fe en el mercado a la fe en el Estado: "Primer acto de la obra La sociedad del riesgo global: Chernóbil. Segundo acto: la amenaza de la catástrofe climática. Tercer acto: el 11-S. Y en el cuarto acto se abre el telón: los riesgos financieros globales. Entran en escena los neoliberales del núcleo duro, quienes ante el peligro se han convertido de repente desde la fe en el mercado a la fe en el Estado"43. Para Beck, "en un mundo de riesgos globales, la consigna del neoliberalismo, que llama a reemplazar la política y el Estado por la economía, se vuelve cada vez menos convincente" ${ }^{\text {"44 }}$.

\footnotetext{
\$1 BARTOLOME RUIZ Castor, Op. Cit, p. 951.

42 BECK Uirich, La sociedad de riesgo global, Siglo XXI, Madrid 2002.

43 BECK Ulrich, De la fe en el mercado a la fe en el Estado, en El País, 15 de abril 2008, Madrid, versión electrónica http://www.elpais.com/articulo/opinion/fe/mercado/fe/Estado/elpepiopi/20080415elpepiopi_11/Tes

44 BECK Ulrich, El fin del neoliberalismo, en El País, 15 de noviembre de 2001, Madrid, consultado en versión electrónica http://www.elpais.com/articulo/opinion/fin/neoliberalismo/elpepiopi/20011115elpepiopi_8/Tes/
} 
Los eventos sintomáticos descritos por Beck son relativamente recientes o muy recientes. La sociedad de riesgo es esta en la que vivimos, cuyos efectos estremecen al mundo más que el conocimiento.

Veamos una última tipificación de nuestras sociedades. Según Gianni Vattimo, la nuestra es la sociedad de la comunicación generalizada, la sociedad de los mass media. Para Vattimo ese es precisamente uno de los aspectos esenciales de la post-modernidad, junto con la superación de la forma lineal de comprender la historia propia de la modernidad ${ }^{45}$.

La modernidad entiende la historia como un progresivo proceso de emancipación, como la realización cada vez más perfecta del ser humano ideal. La historia moderna consiste en el "concatenarse de las vicisitudes protagonizadas por los pueblos de la zona central: el Occidente, que representa el lugar de la civilización, fuera del cual queda lo "primitivo", los pueblos "en vías de desarrollo"46.

Vattimo afirma que la historia como curso unitario es una representación del pasado construida por los grupos y clases sociales dominantes. Y la disolución de la historia entendida como tiempo unitario -con sus consiguientes imperialismos y colonialismos- pone en crisis la idea de progreso: "si no hay un curso unitario de las vicisitudes humanas no podrá sostenerse tampoco que éstas avancen hacia un fin, que efectúen un plan racional de mejoras, educación y emancipación" ${ }^{\prime 4}$.

Junto al fin de la historia entendida como tiempo unitario, hay otro factor determinante para lo que Vattimo llama el fin de la modernidad: se trata del advenimiento de la sociedad de la comunicación. En concreto, lo que Vattimo sostiene es "a) que en el nacimiento de una sociedad

\footnotetext{
45 Cfr. VATTIMO Gianni, La sociedad transparente, Ed. Paidós, Barcelona 1998, f. 73.

46 Ibid, p. 75.

47 Ibid, p. 76.
} 
posmoderna los mass media desempeñan un papel determinante; b) que éstos caracterizan tal sociedad no como una sociedad más "transparente", más consciente de sí misma, más "iluminada", sino como una sociedad más compleja, caótica incluso; y finalmente c) que precisamente en este "caos" relativo residen nuestras esperanzas de emancipación" ${ }^{\prime 48}$.

La razón de tal potencial emancipador es que para Vattimo estos medios han sido determinantes para la disolución de los puntos de vista centrales (los grandes relatos), pues han permitido la explosión y multiplicación generalizada de diversas visiones del mundo ${ }^{49}$. Utilizando los mass media, las culturas han podido tomar la palabra. Ya no hay "una" realidad. Ahora la realidad puede ser entendida como el resultado del entrecruzarse -y contaminarse"- de las múltiples imágenes, interpretaciones y reconstrucciones que sin coordinación "central" alguna, distribuyen los media. De esa manera, según Vattimo, con los mass media se abre camino un ideal de emancipación a cuya base misma están, más bien, la oscilación, la pluralidad, y, en definitiva, la erosión del propio "principio de realidad" 50 . Por eso, para Váttimo, perder el sentido de la realidad -por el multiplicarse de las imágenes del mundo- no es quizá una gran pérdida.

El carácter emancipador de los mass media es resumido por Vattimo con la categoría extrañamiento, entendida como el liberarse todo lo que podríamos llamar, globalmente,

\footnotetext{
$48 \quad$ Ibid, p. 78.

49 Para Vattimo, la emancipación y la liberación que el ser humano siempre ha buscado pasan por el debilitamientu de las estructuras fuertes, una reducción de las pretensiones que implica en general más atención a la calidad que a la cantidad, más escucha de la palabra del otro que visión exacta del objeto. Incluso la verdad, en todos los campos, incluida la ciencia, se convierte en un proceso necesitado de consenso, escucha, participación en una empresa común, más que correspondencia directa con la pura y dura objetividad de las cosas. Esa objetividad -afirma Vatcimo- sólo es posible como resultado de un trabajo social que nos vincula a los otros seres humanos más que a la "realidad" objetiva de las cosas. Cfr. VATTIMO Gianni. Nichilismo ed emacipazione. Etica, politica, diritto, Ed. Garzanti, Milano 2003, p. 46.

50 Ibid, p. 82
} 
el dialecto: "si hablo mi dialecto en un mundo de dialectos seré conciente también de que la mía no es la única "lengua", sino precisamente un dialecto más entre otros. Si profeso mi sistema de valores -religiosos, éticos, políticos, étnicos-en este mundo de culturas plurales, tendré también una aguda conciencia de la historicidad, contingencia y limitación de todos estos sistemas, empezando por el mío" 51 .

Vattimo advierte, sin embargo, que ese efecto emancipador de los media no está garantizado, sino que es sólo una posibilidad -una chance- que hay que apreciar y cultivar, pues ellos pueden ser utilizados también para nuevas formas de colonialismo, como efectivamente vemos que está sucediendo con los grandes monopolios de la industria de la comunicación y con la alianza entre esos monopolios y las grandes empresas transnacionales que son el motor de la actual estrategia de globalización.

Cada calificativo de los arriba mencionados - del conocimiento, de riesgo, de la comunicación, del control, en crisis-, intenta revelar algo del mundo en que vivimos. Así, la utilización de la categoría "sociedad de conocimiento" quiere enfatizar frecuentemente el hecho de que el conocimiento puede tener como consecuencia directa la producción de la riqueza; con categorías como "crisis" y "riesgo" podemos describir las consecuencias indirecta de la relación causal entre conocimiento y riqueza; con la alusión al "control", podemos hacer referencias a estrategias vinculadas a la producción de "sujetos que conocen para producir y para consumir"; con el término comunicación o mass media, podemos referimos a un instrumental cuyo uso puede estar vinculado tanto al control en una sociedad que necesita poner el conocimiento al servicio de la riqueza, como a procesos educativos emancipadores capaces de generar espacios para la recuperación de la voces silenciadas.

51 Ibid, p. 85 . 


\section{4. ¿Cual educación?}

Más arriba me he referido a la postura crítica que los educadores podemos asumir de cara a la pretensión de comprender la escuela a partir de su ajuste a la denominada "sociedad del conocimiento", "sociedad de la información" o "sociedad del aprendizaje", categorías todas frecuentemente utilizadas para describir el tipo de producción de la riqueza correspondiente a la denominada economía postindustrial.

Mi propuesta, frente a tal pretensión se sintetiza en lo que he expresado ya en el título de este trabajo: el contexto en el que educamos hoy exige que los espacios educativos sean capaces de generar lo que Raúl Fornet Betancourt llama "equilibrio epistemológico" ${ }^{52}$. Eso significa, hacer de los ambientes educativos oportunidades para superar las asimetrías que existen entre las diversas culturas del saber. En otras palabras, la escuela-así como los otros espacios en los que se desarrolla una mediación pedagógica- puede constituirse en morada de todas las formas posibles de construcción de saberes y no sólo de aquella vinculada a la adquisición de los conocimientos requeridos para competir en un mercado globalizado.

Si el término "sociedad del conocimiento" indica singularidad - una sola sociedad del conocimiento, con el consecuente riesgo de promover prácticas educativas homogenizadoras-, la expresión "culturas del saber" indica pluralidad. Se trata de admitir, por lo tanto, la diversidad de caminos posibles para la construcción de conocimientos y para el cultivo del saber. Este segunda categoría implica, por lo tanto, la superación del hábito -tan arraigado en los ambientes educativos escolarizados- de deslegitimar los

52 Cfr. FORNET-BETANCOURT Raúl, Transformación intercultural de la filosofía, Ed. Desclée de Brouwer, Bilbao 2001. 
saberes cultivados, los conocimientos construidos y las experiencias vividas antes y fuera del aula.

Hacer de la educación lugar del encuentro de las diversas culturas del saber exigirá, en primer lugar, repensar los fines de la educación y más específicamente, interrogar a esos fines sobre el tipo de sujeto (la cuestión antropológica) y el tipo de mundo (la cuestión cosmológica) al que orientan los procesos educativos. Desde esa doble interrogación podremos verificar al servicio de qué está la educación, o para qué es la mediación. Cuando analizamos las políticas, los sistemas y los planes educativos, podemos fácilmente distinguir en sus fines dos grandes grupos: fines políticos y económicos. Podemos también confirmar que con frecuencia los fines políticos están subordinados a los económicos y que éstos últimos hacen referencia al libre mercado, a la competencia, a la desregulación del comercio, al consumo y a la acumulación. Al servicio de esa subordinación se suelen poner los procesos de construcción de conocimientos. Eso explica la prioridad que se suele dar a la construcción de conocimiento científico-tecnológico, el cual ha sido estrechamente ligado a la acumulación de capital. Detrás de esos fines (políticos y económicos) subyace una antropología individualista -el ser humano des-convocado, competidor, consumidor, centro del universo- y una cosmología que reduce el mundo a mercado en el que hay que competir.

Los fines - políticos y económicos- de la educación pueden ser repensados si entendemos al ser humano como ser viviente, y al mundo como con-vocación de mujeres y hombres con referencias culturales plurales. Se trata de repensar la educación desde un humanismo centrado en la justicia, más que desde un humanismo centrado en la propiedad y la posesión. Desde ese ejercicio de repensar la educación, los fines económicos no se referirán prioritariamente a la acumulación de capital sino a la creación de las condiciones 
necesarias para la reproducción de la vida humana real y concreta $^{53}$; y los fines políticos no se referirán a la formación de sujetos sumisos y disciplinados, sino a la con-vocación y a la vecindad de seres humanos que se interrelacionan desde sus diversidades. De esta manera, el conocimiento construido podrá superar los límites estrechos de lo científicotécnico, y estará más articulado a la vida que al mercado.

En segundo lugar, hacer que la educación se constituya en morada de todas las formas posibles de construcción de saberes es una tarea que exige renovar nuestros hábitos de pensar. Re-aprender a pensar implicará, entonces, aprender a construir conocimiento desde el diálogo y desde la puesta en común de las distintas perspectivas de las personas dialogantes. Tal práctica, a su vez, exige, de parte de los actores, renunciar a considerar la propia perspectiva como la única forma de interpretar el mundo. En la práctica educativa tal renuncia lleva no sólo a acoger los saberes previos, vinculados a la vida, a la propia biografía, a las experiencias y tradiciones comunitarias y las temporalidades contextuales, sino también a generar conocimientos nuevos a partir de esas experiencias, tradiciones, temporalidades y biografías. Los actores de los procesos educativos serán concientes, por lo tanto, de lo condicionado de sus propios procesos de construcción de conocimiento, de su relacionalidad, de su perspectividad y contextualidad. Tales actores, por lo mismo, comunicarán sus saberes, pero no los impondrán.

En tercer lugar, educar superando la violencia epistemológica, implica romper con la reducción del conocimiento a aquél científico-técnico, para reconocer el valor de las diferentes formas de conocimiento construido desde las propias referencias culturas y comunitarias. En este sentido,

\footnotetext{
53 El tema de la reproducción de la vida humana real y concreta es frecuentemente desarrollado por Franz Hinkelammert, por ejemplo en Crítica a la razón utópica, Ed. DEI, San José 2000 .
} 
habría que tomar en serio la reflexión de Vattimo sobre las posibilidades emancipadoras de los medios de comunicación, posibilidades que residen en su capacidad para devolver la voz a los grupos y culturas que han sido obligadas a callar. En esas posibilidades reside también el carácter educativo de los medios.

El conocimiento construido desde el diálogo y conciente de su propia respectividad, es expresión del mundo de la vida, con sus múltiples expresiones, con sus necesidades, sus expectativas y esperanzas, con las reivindicaciones buscadas y no siempre alcanzadas.

Cuando pensamos la educación como ocasión para superar la violencia epistemológica, es decir como espacio para que todas las formas de cultivo del saber tengan lugar, entonces podemos decir que la educación es un derecho (justicia cultural) y no una inversión. Será una inversión, sólo si entendemos el conocimiento fundamentalmente como factor motriz de la "nueva" economía, como objeto mercantilizado que se vuelve rentable mediante la innovación.

Finalmente, desde una educación que acoge todas las formas posibles de construcción del conocimiento y de cultivo de saberes, es posible generar un currículo emancipatorio, que cultive el diálogo y en el que la enseñanza no sea entendida como transmisión, ni el aprendizaje como "un estar de acuerdo". Un currículo es emancipatorio cuando la construcción del conocimiento se basa en metodologías problematizadoras que favorecen el disenso, la disidencia y la rebelión del sujeto que toma conciencia de ser sujeto junto a otros sujetos. Hinkelammert afirma que "en esa rebelión del sujeto reside la esperanza" ${ }^{14}$. Conocer es también producir

54 HINKELAMMERT Franz. El asalto al poder mundial y ha violencia sagrada del imperio, Ed. DEI, San José 2003, p. 62. Para Hinkelammert, la actual estrategia de acumulación de capital necesita una cultura de la desesperanza para poder afirmar su legitimidad. Por eso se presenta como "sin alternativa". Y si no hay alternativa, no hay esperanza. Cfr. Ibid. F. 27 
esperanza, y educar es generar las condiciones para que resurja la esperanza. De alguna manera, por lo tanto, educar es crear condiciones para la rebelión y no para la sumisión.

Con todo lo anterior no pretendemos negar la estrecha relación que existe entre escolaridad y posibilidades de obtener un beneficio económico, ni entre inversión en educación y posibilidades de superación de la pobreza. Es cierto que la aplicación de algunos conocimientos puede ayudar a asegurar una mayor inserción laboral y, en consecuencia, una vida digna. También en innegable que los países que más invierten en educación tienen mayores posibilidades de incrementar los índices de desarrollo humano. Sin embargo, los educadores y educadoras no podemos convertirnos en servidores del mercado laboral; debemos poner la educación al servicio de la vida y no del mercado, concientes de que la mayor parte de los conocimientos que construimos dentro y fuera de la escuela no son económicamente rentables, aunque sean fundamentales para la vida y para la construcción de sentidos y significados: los conocimientos vinculados a las luchas de nuestras comunidades; aquéllos que construimos en el marco de nuestras tradiciones religiosas y de los mitos fundantes de nuestros pueblos; los conocimientos que tienen que ver con nuestras dimensiones ética, estética, histórica y afectiva; los conocimientos fraguados en el encuentro con los otros, en el descubrimiento del rostro del otro y de la otra ${ }^{55}$ dentro y fuera de los ambientes escolarizados; los conocimientos vinculados a los tiempos de la vida y del cosmos, y no sólo aquéllos que tienen que ver con los tiempos de la producción, del consumo, del mercado.

\footnotetext{
55 Sobre el tema de la dimensión ética del ser humana, analizada a partir del reconocimiento del rostro del otro, ver SIDEKUM Antonio, Ética e alteridade. A subjetividade ferida, Ed. UNISINOS, San Leopoldo 2002, p. 141-159.
} 


\section{Referencias bibliográficas}

AGUILAR Edwin, Sociedades del futuro, en El Financiero, San José, 2 de mayo 2005.

Ban Ki-moon, El estado del mundo, en La Nación, 05 de octubre de 2008, versión electrónica http://www.nacion.com/ln_ee/ 2008/octubre/05/opinion1725883.html.

BARTOLOMÉ RUIZ Castor, Sociedad de control, en SALAS Ricardo (coordinador), Pensamiento Crítico Latinoamericano, Vol. III, Ed. UCSH, Santiago 2005.

BECK Ulrich, El fin del neoliberalismo, en El País, 15 de noviembre de 2001, Madrid, consultado en versión electrónica http://www.elpais.com/articulo/opinion/fin/neoliberalismo/ elpepiopi/20011115elpepiopi_8/Tes/

BECK Ulrich, De la fe en el mercado a la fe en el Estado, en El País, 15 de abril 2008, Madrid, versión electrónica http:// www.elpais.com/articulo/opinion/fe/mercado/fe/Estado/elpepiopi/20080415elpepiopi_11/Tes

BECK Ulrich, La sociedad de riesgo global, Siglo XXI, Madrid 2002. CORBÍ Mariano, Proyectar la sociedad, reconvertir la religión, Ed. Herder, Barcelona 1992.

FORNET-BETANCOUR Raúl, Introducción, o de la pregunta: ¿cómo pensar el saber que debemos saber?, documento policopiado.

FORNET BETANCOURT Raúl, La religión y su crisis actual vistas desde la filosofía, en Sociedades de conocimiento: crisis de la religión y retos a la teología. Seminario de teólogos y teólogas, 4-6 de abril del 2005, UNA, Heredia 2006.

FORNET-BETANCOURT Raúl, Transformación Intercultural de la Filosofía, Ed. Desclée de Brouwer, Bilbao 2001.

HINKELAMMERT Franz, Crítica a la razón utópica, Ed. DEI, San José 2000.

HINKELAMMERT Franz, El sujeto y la ley. El retorno del sujeto reprimido, EUNA, San José 2002.

HINKELAMMERT Franz, El asalto al poder mundial y la violencia sagrada del imperio, Ed. DEI, San José 2003. 
ILLICH Iván, En América Latina, ¿para qué sirve la escuela?, Ed. Búsqueda, Buenos Aires 1974.

JOYANES Luis, Cibersociedad. Los retos sociales ante un nuevo mundo digital, Ed. Mc. Graw Hill, Madrid 1997.

NASCIMENTO Jorge, entrevista a Peter Drucker, en Executive Digest, versión digital en http://www.gurusonline.tv/uk/ conteudos/drucker4.asp.

MADRIGAL Rodrigo, Globalización del hambre, en Diario Extra, San José 5 de agosto de 2008, versión electrónica en http:/ /www diarioextra.com/2008/agosto/05/opinion14.php.

MORA Maynor, Avatares del sujeto. Imaginación, intelecto, educación, EUNA, Heredia2005.

RAMONET Ignacio, Las tres crisis, en Le Monde diplomatique (Julio 2008) № 153.

ROBLES Armando, Repensar la religión. De la creencia al conocimiento, EUNA, Heredia 2001.

SANCHEZ Juan José, Escuela, sistema y sociedad, Ed. Libertarias, Medir 1991.

SIDEKUM Antonio, Ética e alteridade. A subjetividade ferida, Ed. UNISINOS, San Leopoldo 2002.

VATTIMO Gianni, La sociedad transparente, Ed. Paidós, Barcelona 1998.

VATTIMO Gianni, Nichilismo ed emacipazione. Etica, politica, diritto, Ed. Garzanti, Milano 2003. 